\title{
3 Research Square \\ Screening the antifungal properties of essential oils against Phytophthora colocasiae
}

\section{Muhammad Talib Kalhoro}

Southwest University of Science and Technology

Hong Zhang ( $\square$ zhanghong316@nwafu.edu.cn )

Southwest University of Science and Technology https://orcid.org/0000-0003-2230-7786

\section{Ghulam Mujtaba Kalhoro}

Southwest University of Science and Technology

Yahya Faqir

Southwest University of Science and Technology

\section{Fukai Wang}

Southwest University of Science and Technology

\section{Farhan Nabi}

Southwest University of Science and Technology

Tianhong Chen

Southwest University of Science and Technology

\section{Zhixian Gao}

Southwest University of Science and Technology

\section{Research Article}

Keywords: Biocontrol, Phytochemicals, Phytophthora colocasiae, Sage and tea tree essential oil

Posted Date: December 29th, 2021

DOI: https://doi.org/10.21203/rs.3.rs-1042822/v1

License: @) (i) This work is licensed under a Creative Commons Attribution 4.0 International License. Read Full License 


\section{Abstract}

Recently Microbicidal and micro-static activities of naturally obtained botanicals have been extensively explored, generally in response to the devastating apprehension of consumers towards the safety of edible products. However, scientists are paying more interest in using bio pesticides and phytochemicals that constitute environmentally favorable, non-toxic, long-lasting, and productive substitutes for preventing many hazardous plant pathogens. This research aimed to investigate the antifungal capabilities of sage and tea tree essential oils towards taro leaf blight, the most important cause of worldwide production losses. Using synthetic fungicides is a rapid and effective approach for controlling plant diseases, but it also creates human health risks, environmental threats, and chances of pathogen resistance. The essential oils of sage and tea tree were obtained by microwave-assisted hydro-distillation, and their chemical components were analyzed using FTIR spectroscopy. The main components of the oil were Thujone and Terpinen-4-ol, in sage and tea, respectively. A casual disease agent isolated from symptomatic taro leaves is used as a test fungus and identified as Phytophthora colocasiae. The antifungal properties of both essential oils were evaluated against mycelium, sporangium, zoospores, leaf necrosis, and corm lesions. Repeated experiments showed that the minimum concentrations for obtaining $100 \%$ inhibition of mycelium, zoospore germination, sporangia formation, and leaf necrosis were estimated at 2.5 and $5.0 \mathrm{mg} / \mathrm{mL}$ of sage and tea tree oils, respectively. Outcomes of this study provide an allusion for the prevention and curation of plant diseases promptly, economically, and environmentally by using phytochemicals and plant essential oil derivatives.

\section{Introduction}

Essential oils (EO), also known as volatiles, ethereal oils, or essences, are biochemical chemicals produced by several different species, most probably plants (Vasconcelos et al., 2019). These oils are commonly obtained using classical approaches, including distillation, pressurizing, or solvent-based extraction (Ali, Chua, \& Chow, 2019). Because of their nature and characteristics, EOs are extensively used in scents, foodstuffs, skincare, and pharmacology (Szutt, Dołhańczuk-Śródka, \& Sporek, 2019). The biochemical makeup of various plant oils varies depending on wherever they grow and particularly on the climatic conditions (Arraiza, 2017). Nevertheless, the essential oil composition may change with the methods employed for drying plant materials, extraction, and distilling process (Merah et al., 2020). These oils are valued for their pleasant fragrance and bioactive components and characteristics (Liao et al., 2017). Essential oils are typically extracted via conventional hydro-distillation (Elyemni et al., 2019), which decreases oil quality and exhibits minimal extraction efficiency when certain volatile compounds can be lost during the extraction and the deprivation of unsaturated compositions temperatures fluctuations and nature of solvents used (Chen et al., 2020). Microwave-assisted extraction, a unique and inventive methodology, has received considerable research and is suitable for small materials and simple and effective control overheated mechanisms (Vinatoru, Mason, \& Calinescu, 2017). The primary advantages of microwave-assisted extracting are affordable, time-saving, eco-friendly, and solvent-free extraction (Y. Wang et al., 2018).

Taro Colocasia esculenta L. is a well-known tuber crop that is extensively grown in many regions of the world, especially China, Africa, and European countries, consumed as a staple food (Ahmed et al., 2020). Taro corms and leaves are rich in carbohydrates, proteins, minerals, and vitamins (Sharma, Jan, Kaur, \& Riar, 2020), and essential elements, including calcium, phosphorus, iron, vitamin C, thiamine, riboflavin, and niacin (Otieno, 
2020). Furthermore, taro has medicinal potentials against several pathogenic diseases and physiological disorders in humans. Taro is vulnerable to over 23 various diseases that negatively impact plant development and production. Taro leaf blight is the most significant damaging of these diseases, resulting in reductions in good crop production (M. E. Bi, Teke, Christopher, Annih, \& Charles, 2020). This disease is very common and has resulted in significant production losses for the crop in different cultivation areas of China (Z. Wang et al., 2021). Phytophthora colocasiae predominantly infects foliar parts of plants, but in severe cases can also appear on petioles and damage the corms of the hosts. The disease develops around 2 to 4 days following infection, during warmer humid climates, and is particularly noticeable on the top portion of plant leaves.

The initial symptoms appear as small, light, or dark brown specks, mainly at the lamina and margins of leaves where water accrues. The patches expand rapidly, fetching spherical, zonate, and purple-brown colors. A watery substance oozes out underneath the spots and appears as a dry gray and solid bubbles like plant exudate. (Jeeva, Veena, Makeshkumar, \& Arutselvan, 2020). In favorable conditions, the disease becomes severe, the lesions become dark brown with yellow edges, and an ash-colored ring of sporangia at the borders of the lesions becomes apparent. Lesions turn papery and drop off under dry and hot environments, causing shot-holes appearance in leaves. However, grown taro leaves become destroyed in few days, dangling like flags and possibly falling on the ground whenever petioles get damaged. The disease causes $50-60 \%$ losses, leading to significant corms deterioration immediately or after harvesting (Takor, Monono, Ntane, Ngale, \& Fontem, 2020).

Phytophthora colocasiae is an oomycete fungus and has a complicated lifecycle depending on growth habits, including hemibiotrophic, biotrophic, and necrotrophic (Alexandra, Jamora, Smale, \& Ghanem, 2020). The survival temperature for pathogen ranges between $15-35^{\circ} \mathrm{C}$. The optimum temperature from $25-30{ }^{\circ} \mathrm{C}$ when the night temperature is around $20^{\circ} \mathrm{C}$, and the moisture content exceeds $90 \%$, encourages zoospore to germinate rapidly, triggering disease outbreaks. $P$. colocasiae is a heterothallic species that produce asexual sporangia, sporangiophores, zoospores, and sexually oospores that become vested in plant debris and corms inoculum for upcoming cropping season. The pathogen overwinters by forming chlamydospores through conversion of thick-walled zoospores, hibernating for persistent viability in the plant debris and corms (Brooks, 2015). Such process enables $P$. colocasieae, as a dangerous pathogen, while continual farming harbors pathogen in field biomass continuously persist in the soil.

The disease can be cured effectively with systemic fungicides, but on the other hand, it creates an immediate risk to human and environmental health as well as long-term consequences on biodiversity and the ecosystem. People are increasingly opting for chemical-free products, particularly those produced in organic agriculture. Thus, researchers focus on bio-pesticides and phytochemicals as eco-friendly, non-hazardous, long-lasting, and effective alternatives to manage plant diseases.

Essential oils or combinations of different phytochemicals exhibit synergistic potential with additional properties against many plant pathogens. This advocates a cost-effective and natural alternative to both agro-food production and consumers, at the same while to the obstacles in innovations to inhibit proliferation of plant pathogens. Sage (salvia sclarea) and tea tree (Melaleuca alternifolia) essential oils contain high antibacterial activities. They are being used as a natural cure and preventive for many plant diseases (Chidi, Bouhoudan, \& Khaddor, 2020; Ebani et al., 2018). As far as our knowledge is concerned, there is no prior 
information for using essential oil from sage and tea tree against taro leaf blight. The present study was designed to explore and develop an easy, compact and effective system for extracting essential oils for convenient and consistent control of plant diseases for sustainable food production.

\section{Materials And Methods}

Freshly collected Sage and tea tree plant materials (leaves, stems) were thoroughly rinsed in sterile water and dried in ventilation under shade at room temperature. Plant parts were crushed into small pieces and soaked in sterilized distilled water overnight before extraction.

\subsection{Extraction of essential oil}

The essential oils of sage and tea trees were obtained using an especially designed microwave-assisted hydro-distillation (MAHD) machine mounted with a Clevenger apparatus. The machine was modified with a swift temperature controller for initial and final heating requirements for different types of plant materials. The idea behind this machine is that microwave breaks the cell wall of plant cells and rupture the cell and swift release of oil components. It operates with a microwave power of 800Watt; rated input wattage; 1000 Watt: operates at a frequency of about $2.4 \mathrm{GHz}$; Maximum Voltage120 volts AC.; maximum temp: $300^{\circ} \mathrm{C}$. The equipment has a digital control panel, a touch LCD, and an automated program to extract different plant oils at different times and temperature requirements. The capacity of the extraction container was 5 Litre and connected to Clevenger with rubber pipes for water circulation. The main advantages of this machine include compact size, need small space, stirring device to homogenize the plant material for constant exposure to microwaves and heating process, which saves extraction time and increase oil yield. The machine is equipped with a water cooling system which increases the condensation efficiency and saving water. The extraction process was carried out at atmospheric pressures, $200 \mathrm{~g}$ of crushed plant material pre-soaked in $300 \mathrm{~mL}$ water and then heated to $80^{\circ} \mathrm{C}$ for 30 minutes in the start and then subsequently increased temperatures to 90,100 and $130^{\circ} \mathrm{C}$ gradients foe every 30 minutes The extraction process was continued unless maximum oil yield was obtained. The extracted oil was collected at the bottom knob of Clevenger and kept in $2 \mathrm{~mL}$ glass tubes, dried with $\left(\mathrm{Na}_{2} \mathrm{SO}_{4}\right)$, and shrouded in tinfoil, stored in the refrigerator.

\subsection{Chemical analysis of extracted essential oils}

The chemical analysis of essential oils was carried out by The FTIR spectra obtained using Spectrum-2 (FT-IR Spectrometer, PerkinElmer USA) interfaced with an ATR (attenuated total reflectance). Samples were fixed as a single drop of E.O. on diamond crystal and Spectra in absorbance mode measured at 600 to $4000 \mathrm{~cm}^{-1}$ with (Thermo Scientific Aldrich Collection of FT-IR Spectra Edition II, USA).

\subsection{Isolation of causal pathogen}

Isolation of disease causal pathogen was performed from infected taro leaves with typical blight symptoms (Figure 2A). leaf pieces $(5 \mathrm{~mm})$ cut from the edge of lesions were surface-sterilized in $1.0 \%$ sodium hypochlorite for 10 minutes and washed twice with sterile distilled water; dried over sterile blotting paper, then placed on freshly prepared V8 agar medium plates and incubated at $25^{\circ} \mathrm{C}$ in a dark growth chamber. When the mycelium appeared from the inoculated leaf fragments, it was aseptically transferred to a new culture 
media to obtain a pure culture (Fig. 2D). The isolated pathogen was identified as Phytophthora colocasiae keeping because of pathogenicity, colony morphology, sporangial characteristics, and microscopic observation of mycelium, as reported by (Evelyn, Charles, Grace, Estella, \& Hanna, 2017; Lucas, 2020). Pathogenicity was established to fulfill Koch's postulates. For maintenance, the cultured was shifted monthly to a new media and kept at $4^{\circ} \mathrm{C}$.

\subsection{Antifungal evaluation of EO in vitro 2.4.1 Mycelial growth inhibition assay}

The fungicidal properties of both essential oils were evaluated for isolated pathogens using the poisoned food approach following Lahlou (2004). The EO were dissolved and homogenized in sterile Dimethyl sulfoxide (DMSO) as a 9:1 (v/v) concentration before supplementation to PDA to achieve final dosages of 5 , $2.5,1.25,0.625,0.312$, and $0.156 \mathrm{mg} / \mathrm{ml}$. Pre-sterile $90 \mathrm{~mm}$ Petri plates filled with $10 \mathrm{ml}$ PDA medium, with four replications for each treatment. PDA plates supplemented with only DMSO were kept as control. In contrast, fungicide (Hymexazol) was supplemented with PDA at a low concentration of $0.156 \mathrm{mg} / \mathrm{ml}$ served as a positive control for comparison. The Petri plates were inoculated with $5 \mathrm{~mm}$ discs from the margins of a freshly produced pure culture of test fungus and incubated at $25^{\circ} \mathrm{C}$ in the dark growth chamber. When the Control treatment Petri plates were full of mycelium growth, the antifungal efficiency of essential oils was determined. Calculation of Mycelium growth inhibition (I) was done with formula $\left\{I=D_{c}-D_{t}\right\}$ where $D_{c}$ is control and $D_{t}$ is treated plates as described by Sameza (2014). The experiment consisted of four replications, and the procedure was performed again to ensure that the results. Complete inhibition of mycelium was determined by placing mycelium plugs inoculated on treated plates to fresh PDA plates for confirmation of inactive inoculum.

\subsubsection{Inhibition of the sporangia production}

In-vitro assessment of sporangium development on Potato Dextrose Broth medium supplemented without and with essential oils at same concentrations described above, for mycelium inhibition assay following (Tchameni et al. 2018). Five mycelial plugs (5 mm) from the center of 7 days fully grown culture of $P$. colocasise, were homogenized in $10 \mathrm{~mL}$ distilled sterile water and centrifuged for 5 minutes at $4000 \mathrm{rpm}$. The sporangia in the supernatant were counted under a light microscope using a haemocytometer in $10 \mu \mathrm{L}$, and inhibition was analyzed by utilizing the formula Is $=\left(N_{0}-N_{t}\right) / N_{t} \times 100$, where $N_{0}$ is the control and $N_{t}$ is the oil treatment. Sporangia counted after 24 hours of incubation at $250 \mathrm{C}$, and release of zoospores was confirmed within 3 hours under fluorescent illumination. The fungicide treatments were maintained as the positive control, and only DMSO treated plates served as a negative control, whereas each treatment consisted of 4 replicates, and the trial was repeated for validation of results.

\subsubsection{Inhibition of Sporangia and zoospore germination assay}

Germination of Sporangia and zoospores assay was performed using the liquid dilution method suggested by Sameza (Sameza et al., 2014) with some modifications. Essential oils were homogenized in DMSO, while Hymexazol diluted in sterile distilled water was added to potato broth medium in test tubes at the previously indicated concentrations with four replications for each treatment. Medium inoculated with pathogen 
suspension $(500 \mu \mathrm{l})$ from a one-week-old culture kept $10^{6}$ cells $/ \mathrm{mL}$ and incubated at $25^{\circ} \mathrm{C}$. Germination of zoospores after $3 \mathrm{~h}$ and sporangia after $24 \mathrm{~h}$ of incubation, counted under a light microscope using a hemocytometer.

\subsubsection{Inhibition of symptoms and sporangia in leaf disc assay}

The leaf necrosis inhibition was carried out with the leaf disc assessment method. Mature taro leaves (two months) harvested from the arboriculture garden were washed in sterile water, surface sterilized with $75 \%$ ethanol for $1 \mathrm{~min}$, and rinsed thoroughly with sterile distilled water. Subsequently, the leaves were cut into a disc shape $(50 \mathrm{~mm})$, immersed in different essential oil for $3 \mathrm{~h}$ at a range of concentrations mentioned above, while leaf discs dipped in DMSO and Hymexazol as the negative and positive control, respectively. Individually treated leaf disc was retained in a $90 \mathrm{~mm}$ petri dish containing moist blotting paper, 4 Petri dished for each treatment and assay repeated for confirmation of results. Thereafter leaf discs were inoculated with $5 \mathrm{~mm}$ discs obtained from 7-day old culture and settled aseptically on the center of leaf lamina and incubated for one week in a dark chamber at $25^{\circ} \mathrm{C}$. Symptoms expression was established on latency period, the diameter of necrosis, and sporangia produced by fungus on the leaf. The disease symptoms inhibition (DSI) of essential oils was assessed with the following formula: $\left.D S I=D_{c}-D_{t} / D_{c}\right) \times 100$, where $D_{t}$ is the lesion diameter with the treatment of essential oils, and $D_{C}$ is the lesion diameter in the negative control.

\subsubsection{Symptoms assessment in taro corms}

Fresh taro corms were harvested from the disease-free field and thoroughly washed with tap water. Uniform size corms with no visible deterioration were selected for the experiment. Thereafter surface sterilization with $1 \%$ sodium hypochlorite $(\mathrm{NaOCl})$, and washed twice in sterile water and dried on blotting paper. Corms were then immersed in previously described concentrations of essential oils for 30 minutes. For pathogen inoculation, Three $\left(5 \mathrm{~mm}^{2}\right)$ plugs were removed aseptically from the top, the central, and bottom axis of corms using a cork borer. The boreholes were injected with $5 \mathrm{~mm}$ mycelial plugs taken from actively growing margins of pure culture of test fungus. The boreholes were sealed with the same plugs previously detached from the same corms. Four corms were used for each treatment, with and without fungicides kept as control, and the experiment was repeated. Inoculated corms were incubated at $25^{\circ} \mathrm{C}$ for 7 days in a dark and moist growth chamber; 7 days later, the corms were cut in vertical axis from the point of inoculation to observe symptoms of fungus invasion.

\subsection{Analysis of Data}

IBM (SPSS 20 Premium Campus Edition) was used for the statistical analysis. The mean \pm standard deviation (S.D.) represents the results. Analysis of variance (ANOVA) was used to express the connection between the variables. The least significant difference (LSD) is used to identify substantial variations in means determined at $\mathrm{P}<0.05$. The graphs were made using the (Graphpad Prism 9) program.

\section{Results And Discussion}

\subsection{Chemical Composition of sage and tea tree essential oil}


Both essential oils obtained by MAHD and analyzed by ATR-FTIR showed main components from sage oil as Thujone (40\%) (Fig. 3A) and tea tree oil contained Terpinen-4-ol (96\%) (Fig. 3B), respectively. Prior research has found the same primary component in sage, as demonstrated by (Radulović et al., 2017), and tea tree (Elmi et al., 2019). The chemical composition of Sage and tea tree essential oils have been widely explored for its numerous pharmacological and non-toxic, and antibacterial properties (Brun, Bernabè, Filippini, \& Piovan, 2019; Yazgan, 2020). Sage and tea trees have a long application history as antimicrobial and antifungal agents (Silveira et al., 2020). Therefore, these oils include a variety of oils having various characteristics, defining their importance in various sectors. Our study focuses on the antifungal properties of these essential oils, while suggestive scientific information has been extensively stated in previous experiments; similarly, revealing and proving fields of application for both oils, as well as their safe use in agriculture, should be considered appropriately.

\subsection{Sage and tea tree E.0. in a mycelial inhibition assay}

The outcomes of our study demonstrate that increasing the use of sage essential oil (SEO) and tea tree oil (TTO) significantly reduced the mycelium elongation of $P$. colocasiae (Fig. 4). The maximum inhibition of fungal radial colony was observed at $5.0 \mathrm{mg} / \mathrm{ml}$ for (SEO) and $1.25 \mathrm{mg} / \mathrm{mL}$ and higher for (TTO). On the other hand, fungicide fully inhibited mycelium growth at a $0.156 \mathrm{mg} / \mathrm{ml}$ dosage with the same situations. The inoculated mycelial discs from treatments with full inhibition were moved to a new culture medium to test the vitality of the mycelium, which was already dead.

The antifungal activity of sage and tea tree oils against $P$. colocasiae has been investigated for the first time. Nonetheless, there have been reports regarding the antibacterial effects of these oils. These oils have a chemically complex content of main and minor components that are important for antibacterial activity and have lately piqued the interest of researchers for their antifungal properties. The previous studies also concluded at Thujone from sage and Terpinen-4-ol from tea tree oil, which has been shown to inhibit many bacterial and fungal pathogens by affecting ATPase cell wall, biological membrane morphology, and intercellular metabolic pathways (Shreaz et al., 2016). However, many studies have shown that Thujone has antifungal properties towards various fungal infections by causing oxidative stress, apoptosis, epigenetic changes, and decreased toxin production (Radulović et al., 2017; Teker et al., 2021). Terpinen-4-ol has been widely reported for its antimicrobial and antifungal properties (Połeć et al., 2019). Therefore, the effectiveness of the remaining minor components in sage and tea tree oil could be not be neglected. In this context, the antifungal activities of essential oils may be related to the synergistic effect of major and minor compounds (D. Wang, Zhang, Jia, Xin, \& Zhai, 2019).

Furthermore, volatile chemicals produced from sage and tea plants may have a role in inhibiting mycelial growth. In general, sage and tea tree oil have been proved to be effective against Candida albicans (Francisconi et al., 2020), Streptococcus agalactiae (Zhang et al., 2018), Sporothrix schenckii (Brilhante et al., 2019), Botrytis cinerea (Li et al., 2020) Aspergillus nigerin grapes by inducing morphous damage and metabolic changes of fungus (An et al., 2019) seed-borne fungi of cucurbits (Moumni et al., 2021)

\subsection{Sage and tea tree E.O. against sporangia and zoospore germination on PDA}


Compared to the controls, germination of Sporangia and zoospores was substantially decreased $(p<0.05)$ and directly correlated to oil concentration (Fig. 4). The lowest inhibitory treatment for sporangia and zoospores was $5.0 \mathrm{mg} / \mathrm{mL}$ of (SEO) and $1.25 \mathrm{mg} / \mathrm{mL}$ of (TTO), with no spore germination noticed in Hymexazol treatment. On the other hand, a significant variation seen in the morphology of sporangia and deformities in zoospores were noticed as observed under a light microscope. This is an indication of the EOinduced breaking down of the cell membrane of sporangia. Sameza (2014) investigated the antifungal effects of eucalyptus E.O. on Pytopthora colocasiae and described zoospores as more susceptible than sporangia (Sameza et al., 2014). Because our findings are consistent with prior research, we can explain this because zoospores lack the biological wall that sporangia do. In favorable circumstances, zoospores germinate by loss of flagellum while becoming encased in a thick wall, leading to the formation of a germ tube initiating the infection process (Matheron \& Porchas, 2000). Antifungal compounds are considered to hamper with molecular mechanism of encystment and cell wall formation (Y. Bi, Jiang, Hausbeck, \& Hao, 2012). The volatile components of E.O. induce vaporization, which may be responsible for this effect. Micromolecules present in essential oils exerts synergistic action inhibiting germination due to aquaphobic characteristics, enabling permeability of cell membranes (Walker \& van West, 2007). Some previous studies are evident for essential oils properties against spore inhibition of several fungi like Aspergillus niger and Aspergillus flavus (Gemeda, Woldeamanuel, Asrat, \& Debella, 2014) A. oryzae, and A. ochraceus (Hu et al., 2019), Fusarium verticillioides, and Alternaria tenuissima (López-Meneses et al., 2017). 
Table 1

Efficacy of sage and tea tree essential oil inhibiting leaf necrosis and sporulation

\begin{tabular}{|c|c|c|c|c|c|c|}
\hline & \multirow{2}{*}{$\begin{array}{l}\text { Essential oils } \\
\text { Concentrations } \\
\mathrm{mg} / \mathrm{ml}\end{array}$} & \multirow{2}{*}{$\begin{array}{l}\text { Latent } \\
\text { time } \\
\text { (Hours) }\end{array}$} & \multicolumn{2}{|l|}{ Necrotic area } & \multicolumn{2}{|c|}{ Sporulation on leaf } \\
\hline & & & $\begin{array}{l}\text { Diameter } \\
(\mathrm{mm})\end{array}$ & $\begin{array}{l}\text { Inhibition } \\
\text { (\%) }\end{array}$ & $\begin{array}{l}10^{6} \\
\text { Sporangia } \\
\mathrm{mL}^{-1}\end{array}$ & Inhibition(\%) \\
\hline Control & 0.0 & 72 & $16.50 \pm 1.58 a$ & $0.00 \pm 0.00 \mathrm{~g}$ & $95.00 \pm 2.58 a$ & $0.00 \pm 0.00 \mathrm{~h}$ \\
\hline \multirow[t]{6}{*}{ Sage } & 0.156 & 72 & $13.17 \pm 0.62 b$ & $20.15 \pm 3.81 f$ & $69.75 \pm 4.57 b$ & $26.57 \pm 4.8 \mathrm{~g}$ \\
\hline & 0.312 & $=$ & $10.60 \pm 0.62 c$ & $35.75 \pm 3.80 \mathrm{e}$ & $43.00 \pm 3.16 d$ & $54.73 \pm 3.32 \mathrm{e}$ \\
\hline & 0.625 & $=$ & $7.20 \pm 0.76 d$ & $56.36 \pm 4.60 \mathrm{~d}$ & $27.00 \pm 1.82 \mathrm{e}$ & $71.57 \pm 1.92 d$ \\
\hline & 1.25 & $=$ & $4.90 \pm 0.98 e$ & $85.58 \pm 2.89 b$ & $12.75 \pm 1.70 f$ & $86.57 \pm 1.79 c$ \\
\hline & 2.5 & $=$ & $3.17 \pm 0.44 \mathrm{fg}$ & $90.66 \pm 1.30 \mathrm{~b}$ & $5.75 \pm 0.95 \mathrm{~g}$ & $93.94 \pm 1.00 \mathrm{~b}$ \\
\hline & 5.0 & $=$ & $0.00 \pm 0.00 \mathrm{~h}$ & $100 \pm 0.00 a$ & $0.00 \pm 0.00 \mathrm{~g}$ & $100 \pm 0.00 a$ \\
\hline \multirow[t]{6}{*}{ Tea tree } & 0.156 & 72 & $12.22 \pm 0.72 b c$ & $25.90 \pm 4.40 f$ & $50.75 \pm 3.5 \mathrm{c}$ & $46.57 \pm 3.68 f$ \\
\hline & 0.312 & $=$ & $7.72 \pm 0.66 d$ & $53.18 \pm 4.03 d$ & $30.25 \pm 3.4 \mathrm{e}$ & $68.15 \pm 3.58 d$ \\
\hline & 0.625 & $=$ & $4.00 \pm 0.41$ ef & $75.75 \pm 2.52 c$ & $14.75 \pm 2.21 f$ & $84.47 \pm 2.33 c$ \\
\hline & 1.25 & $=$ & $2.15 \pm 0.34 \mathrm{~g}$ & $86.96 \pm 2.07 b$ & $0.00 \pm 0.00 \mathrm{~g}$ & $100 \pm 0.00 \mathrm{a}$ \\
\hline & 2.5 & $=$ & $0.00 \pm 0.00 \mathrm{~h}$ & $100 \pm 0.00 a$ & $0.00 \pm 0.00 \mathrm{~g}$ & $100 \pm 0.00 a$ \\
\hline & 5.0 & $=$ & $0.00 \pm 0.00 \mathrm{~h}$ & $100 \pm 0.00 a$ & $0.00 \pm 0.00 \mathrm{~g}$ & $100 \pm 0.00 a$ \\
\hline Hymexazol & 0.156 & 72 & $0.00 \pm 0.00 \mathrm{~h}$ & $100 \pm 0.00 a$ & $0.00 \pm 0.00 \mathrm{~g}$ & $100 \pm 0.00 a$ \\
\hline
\end{tabular}

Values represent means of four replicates, and different letters in the same column denote significant difference as per LSD test $(P<0.05)$, Inhibition percentage compared with negative control.

\subsection{Inhibition of leaf necrosis by E.O.s}

Keeping in incubation for one week, noticeable blight symptoms were observed only on negative control treatments and lower applications of both essential oils $(2.5 \mathrm{mg} / \mathrm{mL}$ or lower). TTO reduced necrotic signs substantially at concentrations of 1.25 and higher (Table 1). On the contrary, leaf discs treated with Hymexazol at $(0.156 \mathrm{mg} / \mathrm{mL})$ as the control treatment and E.O. applications above $5.0 \mathrm{mg} / \mathrm{mL}$ for Sage and $2.5 \mathrm{mg} / \mathrm{ml}$ for tea tree exhibited no apparent symptoms. The findings indicate a significant positive correlation between essential oil treatment and inhibition of symptoms. (Table 1). Keeping aside the mycelial invasion, zoospores germination plays a critical role during the establishment of primary infection. Our findings may be attributed to antifungal chemicals in sage and tea tree essential oils, which lysed zoospores and inhibited germination. Filomena Nazzaro (2017) described that essential oils had been regarded as having the ability to improve plant disease tolerance. The tolerance mechanism is defined as an abrupt release of the responding molecules $\mathrm{H}_{2} \mathrm{O}_{2}$, or oxidative stress, which occurs while plants are treated to any 
biotic or atmospheric pressure (Nazzaro, Fratianni, Coppola, \& Feo, 2017). As previously stated, the significant parts of sage and tea tree essential oil are Thujone and terpinen-4-ol, which have been shown to reduce virulence in various diseases by interference in spore germination by phosphatides dephosphorylation, and peptidases activities inhibiting germ tubes (Khan, Khan, Iqbal, Khan, \& Khan, 2017). This impact may be related to how these chemicals interact with ATPase-dependent efflux mechanisms. It may also inhibit the growth of mycelia and the generation of aflatoxin, which leads to irreversible changes in hyphae formation, decreased cytoplasmic contents, and mitochondrial obliteration (Yu, Wang, Shao, Xu, \& Wang, 2015). The absorption induced by these chemicals is related to the oxidation-reduction process, which regulates particular signaling systems in cells (Sun, Shang, Wang, Lu, \& Liu, 2016).

\subsection{Sage and tea tree E.O. against sporangia production on leaf}

Results revealed that increasing applications of essential oils created a substantial reduction in Sporangia development $(p<0.05)$. (Table 1). Optimal sporangium inhibition was attained at and above $(1.25 \mathrm{mg} / \mathrm{mL}$ $100 \%$ inhibition) of TTO, while SEO prevented sporangia at $5.0 \mathrm{mg} / \mathrm{mL}$ concentration. Furthermore, some morphological changes in sporangia were detected when the application E.O. was enhanced compared to the control treatment. Essential oils include a variety of chemicals that have antifungal properties against a variety of plant pathogenic fungi (D. Wang et al., 2019). These chemicals exhibit various intrusive processes for disease suppression, such as degradation of the cell-wall and lipid bilayer of biological membranes due to high permeability and release of complex biomolecules, which interact with cell membrane activities simultaneously (Shahina et al., 2018). The lipophilic nature of E.O. components enables the oil to penetrate the cell membranes, disrupt enzyme activity, and cause uncontrolled cell wall production. A high proportion of E.O.s containing volatile chemicals induces cell lysis, which inhibits the formation of sporangia (Y. Bi et al., 2012). Several studies have documented the inhibitory consequence of sage and tea tree essential oils on fungal infections; however, it is reasonable to suggest most of the volatile substances produced from the E.O. could inhibit mycelium and sporangial formation. Sporangia production of $P$. colocasiae significantly reduced using E. globulus E.O. at $0.625 \mathrm{mg} / \mathrm{L}$ (Sameza et al., 2014) and C. aurantifolia E.O. at $800 \mathrm{ppm}$ concentration (Tchameni, Mbiakeu, Sameza, Jazet, \& Tchoumbougnang, 2018).

\subsection{Sage and tea tree E.0. inhibiting symptoms in taro corms}

The mycelium plugs implanted in taro corms started to degrade after few days where negative control treatment and $1.25 \mathrm{mg} / \mathrm{mL}$ essential oils or below (Figure 5). Hymexazol treatment and certain essential oil treatments did not produce disease symptoms on corms. The dark brown patches appeared near the inoculation site, which was evident that the corm surface had deteriorated. The suppression of symptoms on taro corms may be due to the high absorption of volatile oils in the fibrous mass of the corms. The increased absorption of volatile oils in the corms pith may explain the reduction of symptoms to taro corms. Taro leaf blight, $P$. colocasiae, causes serious post-harvest destruction of corms (Alexandra et al., 2020).

In comparison, oospores in corms probably stay for a long time, contributing as the massive inoculation that establishes infections eventually proceeds to epidemic scenarios (Baysal-Gurel \& Cinar, 2015). Various techniques and protective and curative capabilities of plant's essential oils are being investigated for the safe and cost-effective treatment of post-harvest infections (Zheng et al., 2019). Although essential oils are often 
used for sanitizing fruits and vegetables, and food items to ensure that they have a long lifetime and are pathogen-free (Sun et al., 2020)

\section{Conclusion}

Following the concerns of systemic fungicides that have beneficial and detrimental adverse effects on human and environmental safety, we performed this study to investigate sage and tea tree essential oil as a suitable replacement for such fungicides. Several plant essential oils with solid antifungal properties must be investigated in this context. This study may serve as a model for efficient, cost-effective, and environmentally favorable managing and controlling plant diseases with botanicals and plant essential oil-derived compounds.

\section{Abbreviations}

ATR: Attenuated total reflectance; DDH20: Double distilled water; DMSO: Dimethyl sulfoxide. DRI: Disease reduction index EO: Essential oil; FTIR: Fourier transform infrared spectroscopy; LCD: Liquid Crystal Display; LSD: least significant difference; MAHD: Microwave assisted hydro-distillation MHz: Megahertz; PDA: Potato dextrose agar; PLC: Programmable Logic Controller; derivative; SEO: Sage Essential Oil; TLB: Taro Leaf Blight; TTO: Tea Tree Oil

\section{Declarations}

\section{Acknowledgment}

The authors are thankful to Qingdao Fudemi biotechnology co Itd for their support.

\section{Funding}

Sichuan oil rape innovation team of national modern agricultural industry technology (SCCXTD-2021-03) supported the research.

\section{Authors' contributions}

MTK, Conceptualization, Data curation; Formal analysis and wrote the original manuscript draft; Z.H. supervised, Funding acquisition; Supervision; Validation, KGM, Visualization; Roles/Writing, F.Y., CH, W.F. and F.N. contributed in review \& editing of this manuscript. All authors read and approved the final manuscript.

\section{Competing interests}

The authors have no any conflict of interest to declare

\section{Data availability statement}

The original contributions presented in the study are included in the article, further inquiries can be directed to the corresponding author/s. 


\section{References}

1. Ahmed I, Lockhart PJ, Agoo EM, Naing KW, Nguyen DV, Medhi DK, Matthews PJ (2020) Evolutionary origins of taro (Colocasia esculenta) in Southeast Asia. Ecology and evolution 10(23):13530-13543. https://doi.org/10.1002/ece3.6958

2. Alexandra S, Jamora N, Smale M, Ghanem ME (2020) The tale of taro leaf blight: A global effort to safeguard the genetic diversity of taro in the Pacific. Food Security 12:1005-1016. https://doi.org/10.1007/s12571-020-01039-6

3. Ali A, Chua BL, Chow YH (2019) An insight into the extraction and fractionation technologies of the essential oils and bioactive compounds in Rosmarinus officinalis L.: Past, present and future. TRAC Trends Anal Chem 118:338-351. https://doi.org/10.1016/j.trac.2019.05.040

4. An P, Yang X, Yu J, Qi J, Ren X, Kong Q (2019) a-Terpineol and terpene-4-ol, the critical components of tea tree oil, exert antifungal activities in vitro and in vivo against Aspergillus niger in grapes by inducing morphous damage and metabolic changes of fungus. Food Control 98:42-53. https://doi.org/10.1016/j.foodcont.2018.11.013

5. Arraiza MP (2017) Medicinal and aromatic plants: the basics of industrial application, vol 1. Bentham Science Publishers

6. Baysal-Gurel F, Cinar A (2015) First Report of Leaf Blight Caused by Phytophthora colocasiae Infecting Taro in Turkey. Plant Dis 99(10):1445. https://doi.org/10.1094/PDIS-12-14-1311-PDN

7. Bi ME, Teke AN, Christopher S, Annih MG, Charles F (2020) Evaluation of Fungicide against Taro Leaf Blight Disease Caused by Phytophthora colocasiae in Three Agro-Ecological Zones of Cameroon. Asian Research Journal of Agriculture 1-12. 10.9734/arja/2020/v13i330102

8. Bi Y, Jiang H, Hausbeck MK, Hao JJ (2012) Inhibitory effects of essential oils for controlling Phytophthora capsici. Plant Dis 96(6):797-803. https://doi.org/10.1094/PDIS-11-11-0933

9. Brilhante RS, Pereira VS, Oliveira JS, Rodrigues AM, de Camargo ZP, Pereira-Neto WA, Sidrim JJ (2019) Terpinen-4-ol inhibits the growth of Sporothrix schenckii complex and exhibits synergism with antifungal agents. Future Microbiol 14(14):1221-1233

10. Brooks F (2015) Taro leaf blight. The Plant Health Instructor. DOI: 10.1094. PHI-I-2005-0531-01

11. Brun P, Bernabè G, Filippini R, Piovan A (2019) In vitro antimicrobial activities of commercially available tea tree (Melaleuca alternifolia) essential oils. Curr Microbiol 76(1):108-116. https://doi.org/10.1007/s00284-018-1594-x

12. Chen F, Liu S, Zhao Z, Gao W, Ma Y, Wang X, Luo D (2020) Ultrasound pre-treatment combined with microwave-assisted hydrodistillation of essential oils from Perilla frutescens (L.) Britt. leaves and its chemical composition and biological activity. Ind Crops Prod 143:111908. https://doi.org/10.1016/j.indcrop.2019.111908

13. Chidi F, Bouhoudan A, Khaddor M (2020) Antifungal effect of the tea tree essential oil (Melaleuca alternifolia) against Penicillium griseofulvum and Penicillium verrucosum. Journal of King Saud University-Science 32(3):2041-2045. https://doi.org/10.1016/j.jksus.2020.02.012

14. Ebani VV, Nardoni S, Bertelloni F, Giovanelli S, Ruffoni B, D’Ascenzi C, Mancianti F (2018) Activity of Salvia dolomitica and Salvia somalensis essential oils against bacteria, molds and yeasts. Molecules 
23(2):396. https://doi.org/10.3390/molecules23020396

15. Elmi A, Ventrella D, Barone F, Carnevali G, Filippini G, Pisi A, Bacci ML (2019) In vitro effects of tea tree oil (Melaleuca Alternifolia essential oil) and its principal component terpinen-4-ol on swine spermatozoa. Molecules 24(6):1071. https://doi.org/10.3390/molecules24061071

16. Elyemni M, Louaste B, Nechad I, Elkamli T, Bouia A, Taleb M, Eloutassi N (2019) Extraction of essential oils of Rosmarinus officinalis L. by two different methods: Hydrodistillation and microwave assisted hydrodistillation. The Scientific World Journal, 2019 https://doi.org/10.1155/2019/3659432

17. Evelyn M, Charles F, Grace M, Estella T-F, Hanna R (2017) Evaluation of Latent Infection, Bio-deterioration and Yield of Colocasia esculenta (L.) Schott, Caused by Taro Leaf Blight Disease (Phytophthora colocasiae Raciborski). Journal of Advances in Biology \& Biotechnology 1-10.

10.9734/JABB/2017/16479

18. Francisconi RS, Huacho PMM, Tonon CC, Bordini EAF, Correia MF, Sardi JdCO, Spolidorio DMP (2020) Antibiofilm efficacy of tea tree oil and of its main component terpinen-4-ol against Candida albicans. Brazilian Oral Research 34. https://doi.org/10.1590/1807-3107bor-2020.vol34.0050

19. Gemeda N, Woldeamanuel Y, Asrat D, Debella A (2014) Effect of essential oils on Aspergillus spore germination, growth and mycotoxin production: a potential source of botanical food preservative. Asian Pacific journal of tropical biomedicine 4:S373-S381. https://doi.org/10.12980/APJTB.4.2014C857

20. Hu F, Tu X-F, Thakur K, Hu F, Li X-L, Zhang Y-S, Wei Z-J (2019) Comparison of antifungal activity of essential oils from different plants against three fungi. Food Chem Toxicol 134:110821. https://doi.org/10.1016/j.fct.2019.110821

21. Jeeva M, Veena S, Makeshkumar T, Arutselvan R (2020) Potential Strategies to Mitigate Emerging Diseases of Tropical Tuber Crops. Harnessing the Potential of Tropical Tuber Crops,70https://www.ctcri.org/publications/hpttc_ps.pdf

22. Khan SN, Khan S, Iqbal J, Khan R, Khan AU (2017) Enhanced killing and antibiofilm activity of encapsulated cinnamaldehyde against Candida albicans. Front Microbiol 8:1641. https://doi.org/10.3389/fmicb.2017.01641

23. Li Z, Shao X, Wei Y, Dai K, Xu J, Xu F, Wang H (2020) Transcriptome analysis of Botrytis cinerea in response to tea tree oil and its two characteristic components. Appl Microbiol Biotechnol 104(5):21632178. https://doi.org/10.3389/fmicb.2017.01641

24. Liao M, Xiao JJ, Zhou LJ, Yao X, Tang F, Hua RM, Cao HQ (2017) Chemical composition, insecticidal and biochemical effects of Melaleuca alternifolia essential oil on the Helicoverpa armigera. J Appl Entomol 141(9):721-728. https://doi.org/10.1111/jen.12397

25. López-Meneses AK, Sánchez-Mariñez RI, Quintana-Obregón EA, Parra-Vergara NV, González-Aguilar GA, López-Saiz CM, Cortez-Rocha MO (2017) In vitro antifungal activity of essential oils and major components against fungi plant pathogens. J Phytopathol 165(4):232-237.

https://doi.org/10.1111/jph.12554

26. Lucas JA (2020) Plant pathology and plant pathogens. John Wiley \& Sons

27. Matheron M, Porchas M (2000) Impact of azoxystrobin, dimethomorph, fluazinam, fosetyl-Al, and metalaxyl on growth, sporulation, and zoospore cyst germination of three Phytophthora spp. Plant Dis 
84(4):454-458. https://doi.org/10.1094/PDIS.2000.84.4.454

28. Merah O, Sayed-Ahmad B, Talou T, Saad Z, Cerny M, Grivot S, Hijazi A (2020) Biochemical composition of cumin seeds, and biorefining study. Biomolecules 10(7):1054. https://doi.org/10.3390/biom10071054

29. Moumni M, Romanazzi G, Najar B, Pistelli L, Amara B, Mezrioui H, Allagui K, M. B (2021) Antifungal activity and chemical composition of seven essential oils to control the main seedborne fungi of cucurbits. Antibiotics 10(2):104. https://doi.org/10.3390/antibiotics10020104

30. Nazzaro F, Fratianni F, Coppola R, Feo VD (2017) Essential oils and antifungal activity. Pharmaceuticals 10(4):86. https://doi.org/10.3390/ph10040086

31. Otieno CA (2020) Taro Leaf Blight (Phytophthora colocasiae) Disease Pathogenicity on Selected Taro. Colocasiae esculenta) Accessions in Maseno, Kenya

32. Połeć K, Wójcik A, Flasiński M, Wydro P, Broniatowski M, Hąc-Wydro K (2019) The influence of terpinen-4ol and eucalyptol-The essential oil components-on fungi and plant sterol monolayers. Biochimica et Biophysica Acta (BBA)-Biomembranes 1861(6):1093-1102.

https://doi.org/10.1016/j.bbamem.2019.03.015

33. Radulović NS, Genčić MS, Stojanović NM, Randjelović PJ, Stojanović-Radić ZZ, Stojiljković NI (2017) Toxic essential oils. Part V: Behaviour modulating and toxic properties of thujones and thujonecontaining essential oils of Salvia officinalis L., Artemisia absinthium L., Thuja occidentalis L. and Tanacetum vulgare L. Food Chem Toxicol 105:355-369. https://doi.org/10.1016/j.fct.2017.04.044

34. Sameza ML, Boat MAB, Nguemezi ST, Mabou LCN, Dongmo PMJ, Boyom FF, Menut C (2014) Potential use of Eucalyptus globulus essential oil against Phytophthora colocasiae the causal agent of taro leaf blight. Eur J Plant Pathol 140(2):243-250. https://doi.org/10.1007/s10658-014-0457-y

35. Shahina Z, El-Ganiny AM, Minion J, Whiteway M, Sultana T, Dahms TE (2018) Cinnamomum zeylanicum bark essential oil induces cell wall remodelling and spindle defects in Candida albicans. Fungal biology and biotechnology 5(1):1-16. https://doi.org/10.1186/s40694-018-0046-5

36. Sharma S, Jan R, Kaur R, Riar CS (2020) Taro (Colocasia esculenta). Antioxidants in Vegetables and Nuts-Properties and Health Benefits. Springer, pp 341-353. https://doi.org/10.1007/978-981-15-74702_18

37. Shreaz S, Wani WA, Behbehani JM, Raja V, Irshad M, Karched M, Hun LT (2016) Cinnamaldehyde and its derivatives, a novel class of antifungal agents. Fitoterapia 112:116-131.

https://doi.org/10.1016/j.fitote.2016.05.016

38. Silveira MP, Silva HC, Pimentel IC, Poitevin CG, Costa Stuart AK, Carpiné D, Jorge RMM (2020) Development of active cassava starch cellulose nanofiber-based films incorporated with natural antimicrobial tea tree essential oil. Journal of Applied Polymer Science, 137(21), 48726 https://doi.org/10.1002/app.48726

39. Sun Q, Li J, Sun Y, Chen Q, Zhang L, Le T (2020) The antifungal effects of cinnamaldehyde against Aspergillus niger and its application in bread preservation. Food Chem 317:126405. https://doi.org/10.1016/j.foodchem.2020.126405

40. Sun Q, Shang B, Wang L, Lu Z, Liu Y (2016) Cinnamaldehyde inhibits fungal growth and aflatoxin B 1 biosynthesis by modulating the oxidative stress response of Aspergillus flavus. Appl Microbiol Biotechnol 
100(3):1355-1364. DOI: 10.1007/s00253-015-7159-z

41. Szutt A, Dołhańczuk-Śródka A, Sporek M (2019) Evaluation of chemical composition of essential oils derived from different Pelargonium species leaves. Ecol Chem Eng 26(4):807-816. DOI:10.1515/eces2019-0057

42. Takor MC, Monono EY, Ntane OA, Ngale JE, Fontem LA (2020) Assessing Taro (Colocasia esculenta (L.) Schott) Leaf Blight Incidence, Severity, and Farmers' Knowledge of the Disease in Fako Division of Cameroon. International Journal of Pathogen Research 5(2):17-29. 10.9734/ijpr/2020/v5i230128

43. Tchameni SN, Mbiakeu SN, Sameza ML, Jazet PMD, Tchoumbougnang F (2018) Using Citrus aurantifolia essential oil for the potential biocontrol of Colocasia esculenta (taro) leaf blight caused by Phytophthora colocasiae. Environ Sci Pollut Res 25(30):29929-29935. https://doi.org/10.1007/s11356-017-0506-0

44. Teker T, Sefer Ö, Gazdağlı A, Yörük E, Varol G, Albayrak G (2021) a-Thujone exhibits an antifungal activity against $F$. graminearum by inducing oxidative stress, apoptosis, epigenetics alterations and reduced toxin synthesis. Eur J Plant Pathol 1-12. https://doi.org/10.1007/s10658-021-02269-w

45. Vasconcelos LC, de Souza Santos E, de Oliveira Bernardes C, da Silva Ferreira MF, Ferreira A, Tuler AC, Praça-Fontes MM (2019) Phytochemical analysis and effect of the essential oil of Psidium L. species on the initial development and mitotic activity of plants. Environ Sci Pollut Res 26(25):26216-26228. https://doi.org/10.1007/s11356-019-05912-6

46. Vinatoru M, Mason T, Calinescu I (2017) Ultrasonically assisted extraction (UAE) and microwave assisted extraction (MAE) of functional compounds from plant materials. TRAC Trends Anal Chem 97:159-178. https://doi.org/10.1016/j.trac.2017.09.002

47. Walker CA, van West $P$ (2007) Zoospore development in the oomycetes. Fungal biology reviews 21(1):10-18. https://doi.org/10.1016/j.fbr.2007.02.001

48. Wang D, Zhang J, Jia X, Xin L, Zhai H (2019) Antifungal effects and potential mechanism of essential oils on Collelotrichum gloeosporioides in vitro and in vivo. Molecules 24(18):3386

49. Wang Y, Li R, Jiang Z-T, Tan J, Tang S-H, Li T-T, Li J-T (2018) Green and solvent-free simultaneous ultrasonic-microwave assisted extraction of essential oil from white and black peppers. Ind Crops Prod 114:164-172. https://doi.org/10.3390/molecules24183386

50. Wang Z, Bao J, Lv L, Lin L, Li Z, Shi M, Li B (2021) Genome Sequence Resource of Phytophthora colocasiae from China Using Nanopore Sequencing Technology. Plant Disease(ja) https://doi.org/10.1094/PDIS-11-20-2327-A

51. Yazgan H (2020) Investigation of antimicrobial properties of sage essential oil and its nanoemulsion as antimicrobial agent. LWT 130:109669. https://doi.org/10.1016/j.Iwt.2020.109669

52. Yu D, Wang J, Shao X, Xu F, Wang H (2015) Antifungal modes of action of tea tree oil and its two characteristic components against Botrytis cinerea. J Appl Microbiol 119(5):1253-1262. https://doi.org/10.1111/jam.12939

53. Zhang Y, Feng R, Li L, Zhou X, Li Z, Jia R, He C (2018) The antibacterial mechanism of terpinen-4-ol against Streptococcus agalactiae. Curr Microbiol 75(9):1214-1220. https://doi.org/10.1007/s00284-018$1512-2$ 
54. Zheng J, Liu T, Guo Z, Zhang L, Mao L, Zhang Y, Jiang H (2019) Fumigation and contact activities of 18 plant essential oils on Villosiclava virens, the pathogenic fungus of rice false smut. Sci Rep 9(1):1-10. https://doi.org/10.1038/s41598-019-43433-x

\section{Figures}

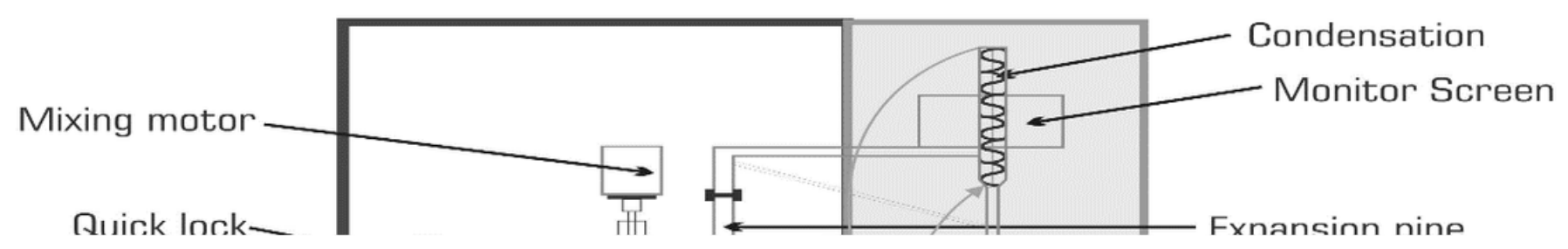

Figure 1

MAHD model design 

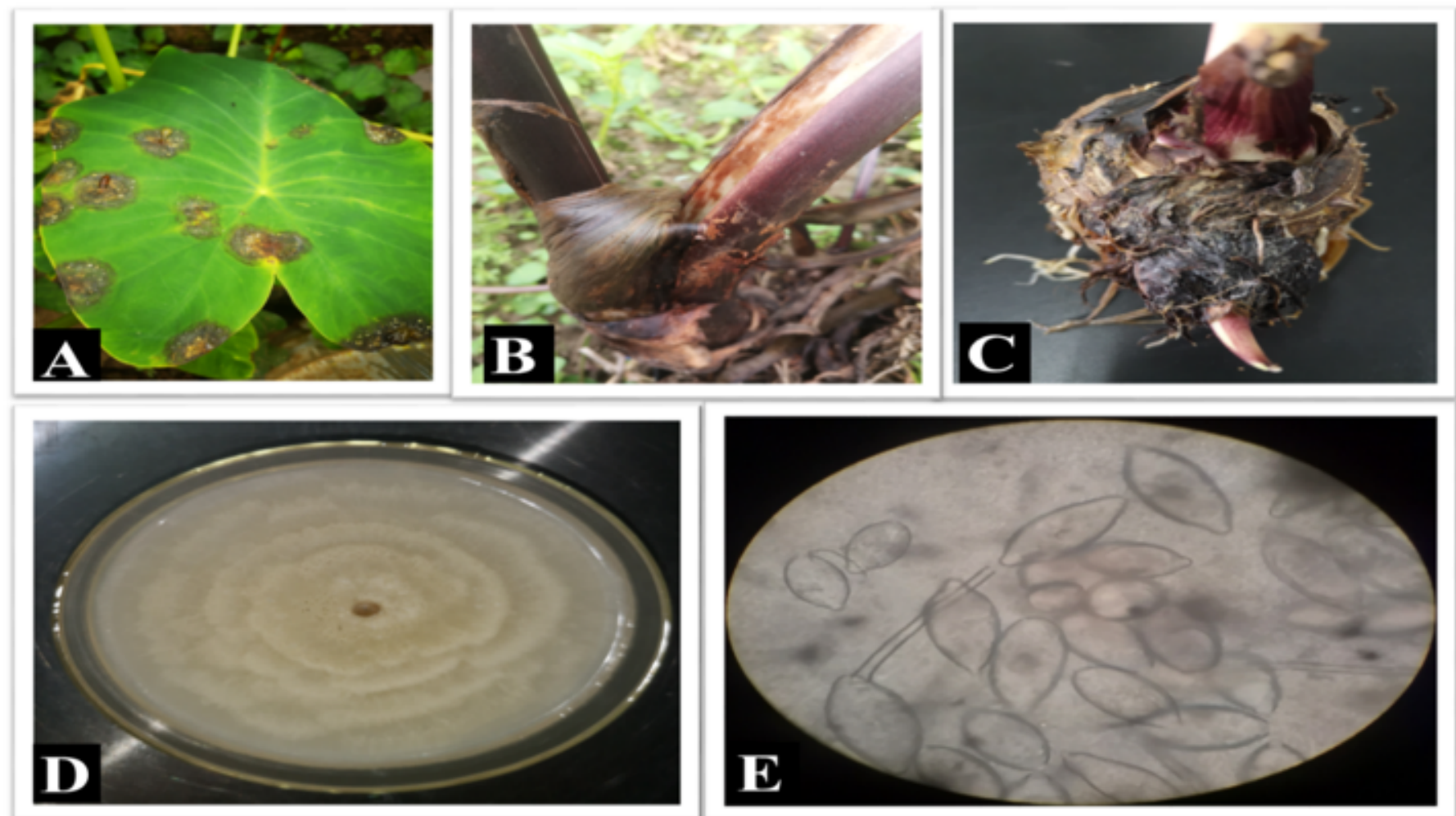

Figure 2

TLB Disease symptoms and morphology of $P$. colocasiae. A Characteristic Symptoms of TLB, B, Abrasions on leaf petioles, C, Infected Corms, D, Mycelium growth pattern E, Sporangia under the microscope, 


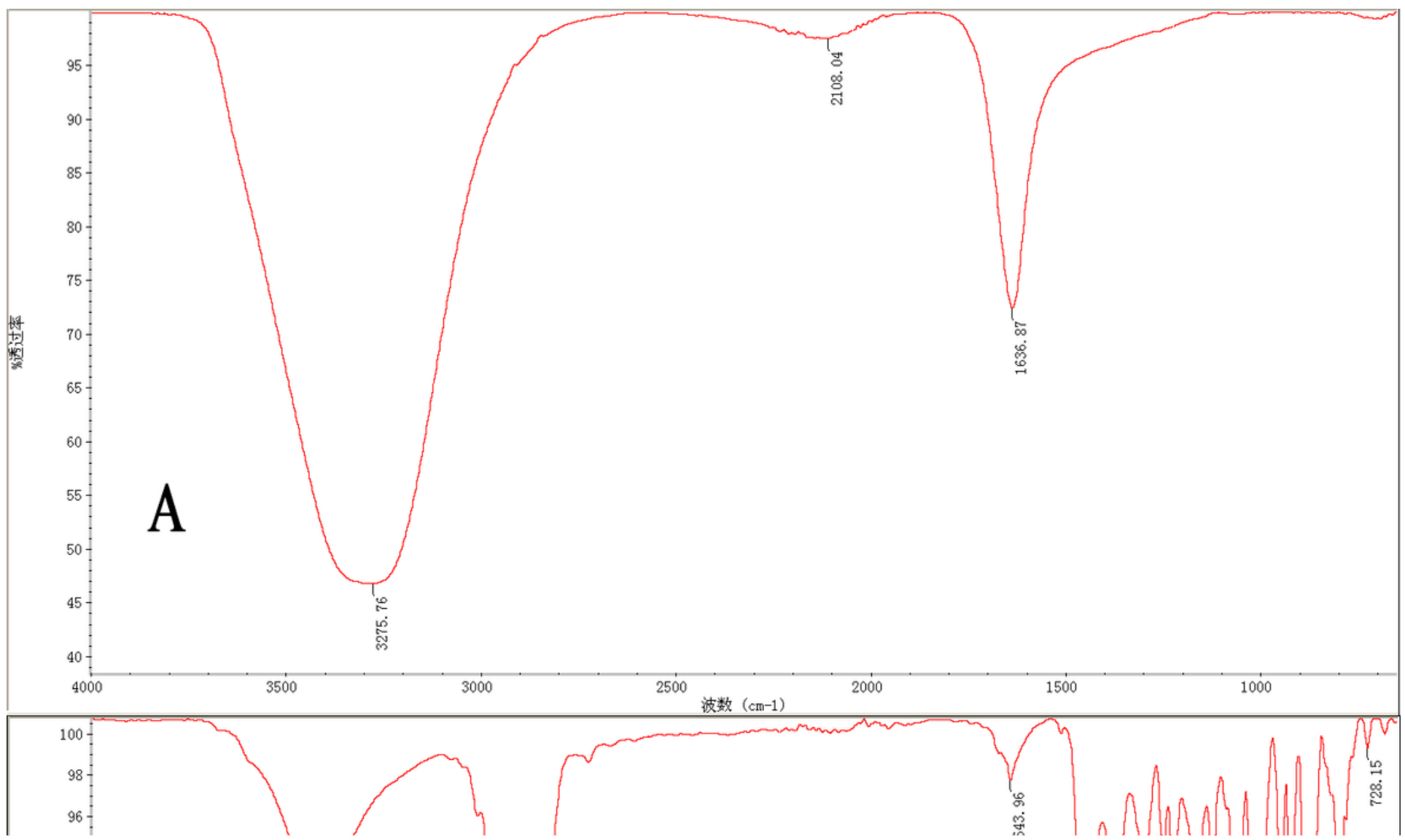

\section{Figure 3}

FTIR spectra of (a) sage and (b) tea tree essential oils 

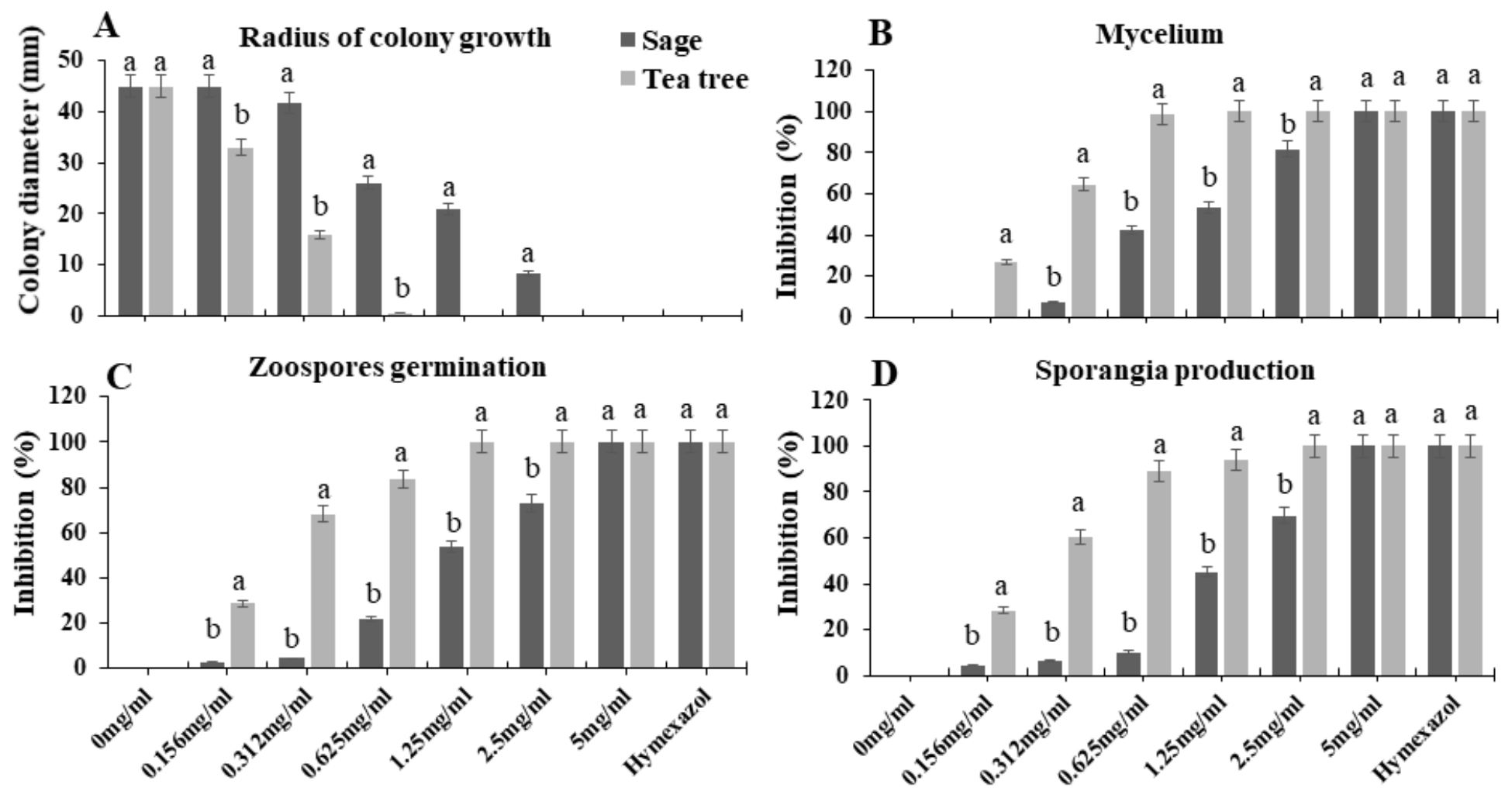

Treatments

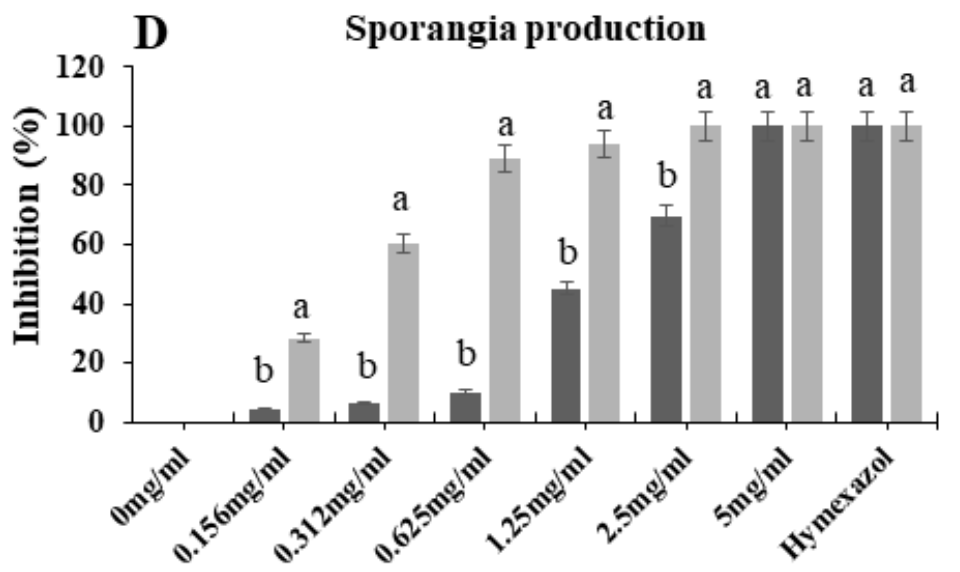

Treatments

Figure 4

Efficacy of E.O.s in mycelial and spore germination inhibition

Values represent the means of four replicates, and different letters on bars denote significant differences as per the LSD test $(P<0.05)$.

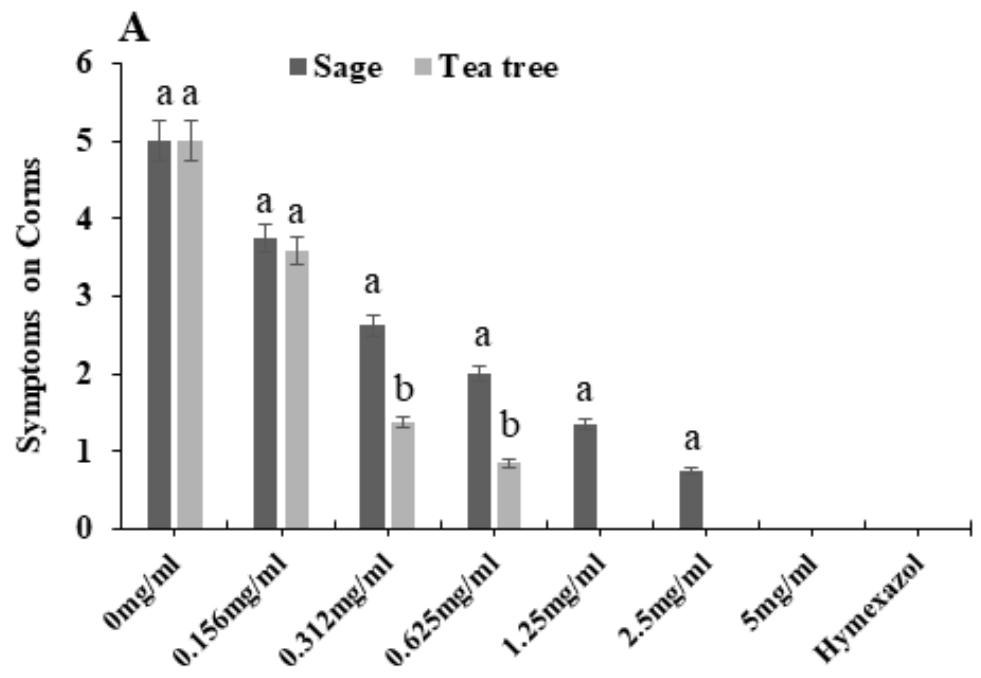

Treatments

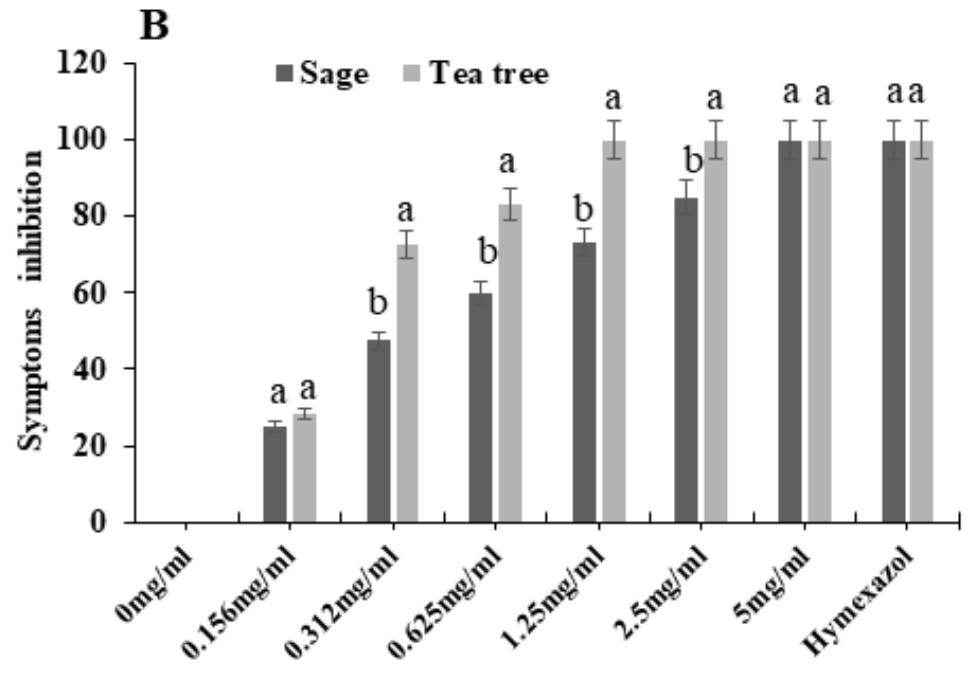

Treatments

Figure 5 
Efficacy of sage and tea tree E.O. inhibition of symptoms on taro corms.

Note: Dissimilar letters denote significantly different as per LSD test $(P<0.05) \mathrm{N}$

Symptoms measured as mycelium invasion in boreholes $(\mathrm{mm})$ 